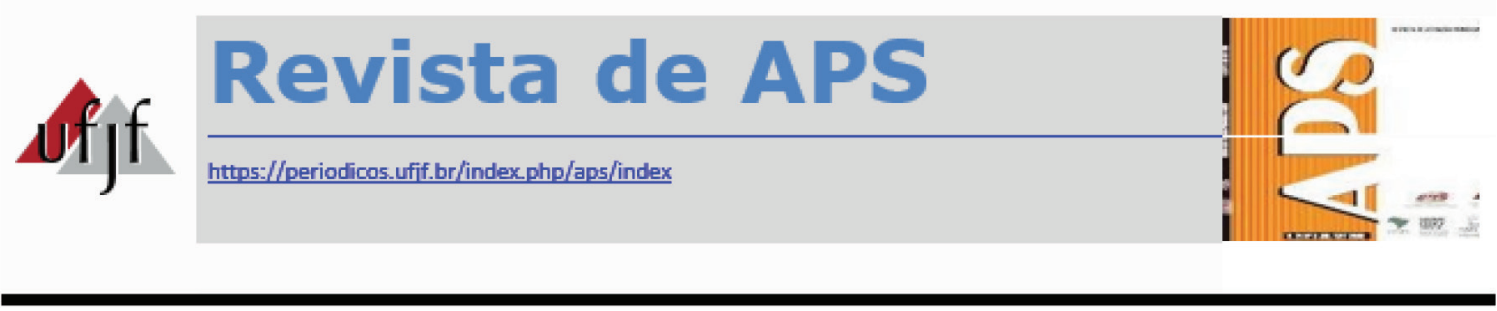

\title{
Os processos educativos em grupos comunitários como caminhos para a promoção da saúde e da segurança alimentar e nutricional na Atenção Básica
}

\section{Educational processes in community groups as pathways to Health Promotion and Food and Nutrition Security in Primary Care}

Pedro José Santos Carneiro Cruz ${ }^{1}$, Mário César Xavier Filho², Renan Soares Araújo³, Gabriel Nóbrega Vieira ${ }^{4}$, João Batista Oliveira ${ }^{5}$, Ana Cláudia Cavalcanti Peixoto de Vasconcelos ${ }^{6}$

\begin{abstract}
RESUMO
O presente trabalho buscou explicitar saberes e práticas da Promoção da Saúde (PS) e da Segurança Alimentar e Nutricional (SAN) no âmbito da Atenção Básica (AB), partindo de processos educativos em grupos comunitários pautados pela perspectiva da Educação Popular (EP). O processo investigativo baseou-se na sistematização de experiências, tendo como foco atividades desenvolvidas no período de dez anos (2007-2017) pelo Programa de Extensão “Práticas Integrais de Promoção da Saúde e Nutrição na Atenção Básica (PINAB)", o qual é vinculado à Universidade Federal da Paraíba e é construído de forma compartilhada com trabalhadores e usuários de uma Unidade de Saúde da Família. Empregou-se a pesquisa documental como forma de mobilização de fontes para essa sistematização. Como resultado, pôdese apontar: os pressupostos que sustentaram essa experiência, as formas de organização da mesma, os desafios e as potencialidades de seus processos educativos.
\end{abstract}

PALAVRAS-CHAVE: Promoção da Saúde. Programas e Políticas de Nutrição e Alimentação. Atenção Primária à Saúde. Educação em Saúde. Participação da Comunidade.

\footnotetext{
${ }_{1}^{1}$ Professor da Universidade Feaderal da Paraíba (UFPB). Doutor em Educação. ORCID: https://orcid.org/0000-00030610-3273 E-mail: pedrojosecruzpb@yahoo.com.br

${ }^{2}$ Graduando em Medicina pela Universidade Federal da Paraíba.

${ }^{3}$ Mestre em Educação (2021) pelo Programa de Pós-Graduação em Educação (PPGE), da Universidade Federal da Paraíba (UFPB). Graduado em Nutrição (2019) pela UFPB. ORCID: https://orcid.org/0000-0002-3477-638X

${ }^{4}$ Graduando em Fisioterapia. Universidade Federal da Paraíba. ORCID: https://orcid.org/0000-0002-7393-3958

${ }^{5}$ Universidade Federal da Paraíba. Graduando em Farmácia. ORCID: https://orcid.org/0000-0001-7254-2931

${ }^{6}$ Mestra em Saúde Pública pela Universidade de São Paulo e doutora em Ciências pela ENSP/FIOCRUZ. Professora da Universidade Federal da Paraíba. ORCID: https://orcid.org/0000-0003-0450-8760
} 


\begin{abstract}
The present work sought to explain knowledge and practices of Health Promotion (PS) and Food and Nutritional Security (SAN) within the scope of Primary Care $(A B)$, starting from educational processes in community groups based on the perspective of Popular Education (EP). The investigative process was based on the systematization of experiences, focusing on activities developed in the ten-year period (2007-2017) by the Extension Program "Comprehensive Practices for the Promotion of Health and Nutrition in Primary Care (PINAB)", which is linked to the Federal University of Paraíba and is built in a shared way with workers and users of a Family Health Unit. Documentary research was used as a way of mobilizing sources for this systematization. As a result, it was possible to point out: the assumptions that sustained this experience, the organization forms of it, the challenges and the potential of its educational processes.
\end{abstract}

KEYWORDS: Health Promotion. Nutrition Programs and Policies. Primary Health Care. Health Education. Community Participation.

\title{
INTRODUÇÃO
}

A Carta de Ottawa, redigida no contexto da Primeira Conferência Internacional sobre Promoção da Saúde, em novembro de 1986, estabeleceu consenso de que a Promoção da Saúde (PS) constitui "processo de capacitação da comunidade para atuar na melhoria de sua qualidade de vida e saúde, incluindo uma maior participação no controle deste processo". ${ }^{1}$

Alguns autores observam que, mesmo após três décadas decorridas desse marco fundamental da saúde global, a análise da dinâmica dos processos de mobilização, formação e construção social em PS constitui uma preocupação fundamental. ${ }^{2}$ Devese aprimorar a possibilidade de o setor saúde não se restringir à cura e reabilitação, integrando esses esforços com a prevenção, a educação e a participação comunitária, por meio de espaços sociais de construção de iniciativas para a qualidade de vida com integralidade, humanização e amplitude. ${ }^{3}$

Pinheiro aponta que o percurso investigativo que nos leva a procurar os caminhos e desafios para a PS na atual realidade dos serviços de Atenção Básica pressupõe, necessariamente, um estudo cuidadoso acerca da interface desse campo com o da Segurança Alimentar e Nutricional (SAN). ${ }^{4}$ Tal campo, nas últimas décadas, tem deflagrado consideráveis avanços conceituais e políticos na discussão em torno da alimentação enquanto direito humano e de sua relevância como referencial aglutinador e integrador da luta contra a fome e a pobreza no cotidiano da execução e operacionalização de outras políticas sociais, particularmente a saúde. ${ }^{5}$

Esse cenário demandou uma notável transformação na abordagem governamental deste problema, a partir do momento em que passaram a ser construídas novas perspectivas teóricas e outros conceitos orientadores de políticas e ações 
para o enfrentamento destas questões. Vasconcelos indica marcos políticos e sociais significativos nesse sentido, a saber: a reformulação do Conselho Nacional de SAN, a criação do Programa Fome Zero, a criação do Ministério do Desenvolvimento Social e Combate à Fome (MDS), a realização da II e da III Conferência Nacional de SAN. Com a Lei Orgânica de SAN (LOSAN), a SAN passou a ser entendida como um fenômeno cujo enfrentamento não pode prescindir de caminhos como a intersetorialidade e o diálogo interdisciplinar. ${ }^{6}$

No campo da SAN, muito se tem escrito sobre aportes teóricos para novas dimensões e abordagens na ação educativa em Nutrição, bem como na reorientação da prática profissional do nutricionista. Além disso, nos últimos treze anos houve um avanço significativo no que tange à expressão e à capilaridade de políticas sociais públicas de combate à fome e à pobreza e de promoção à alimentação saudável. Mas, em que pesem as publicações e legislações, ainda é necessário maior avanço no tocante à necessidade de os aspectos teóricos da SAN se aprofundarem em dimensões práticas, especificamente quanto à efetivação de experiências transformadoras da nutrição social como prática social e profissional.

Dessa forma, é urgente produzir reflexões que extrapolem a intenção de consolidar o discurso progressista em torno da nutrição (particularmente, por meio da perspectiva da SAN e da Educação Alimentar e Nutricional - EAN - crítica) e rumem no sentido de pensar potencialidades e desafios para a construção dinâmica das práticas sociais e profissionais em Nutrição. Precisamos pensar não somente "o que" fazer, mas "como", "por quê", "com quem" e "com que intencionalidade política" fazer as ações de SAN. Para tanto, é fundamental pautar-se as realizações práticas da SAN, explicitando seus caminhos com clareza e efetividade, de modo que possam ser trilhados na direção de sua contribuição para a geração plena da alimentação saudável como direito humano, exercido cotidianamente e de maneira articulada à realidade de cada território, não dissociada do empoderamento e da qualidade de vida e saúde das pessoas.

Assim, a partir da apresentação de uma experiência, adentrando nas suas descobertas e possibilidades, o presente artigo está compromissado com a explicitação de práticas educacionais e seus processos na PS e na SAN. Para tanto, propomos um debruçar sobre processos desenvolvidos há dez anos no âmbito de um serviço de Atenção Básica, além de equipamentos sociais articulados a esse serviço, movimentos e comunidades populares, e instituições sociais públicas parceiras de um Programa de Extensão da Universidade Federal da Paraíba (UFPB).

Este trabalho, portanto, foi construído no contexto de uma pesquisa cujo objeto central foi a PS e a SAN no âmbito da Atenção Básica, especificamente na Estratégia Saúde da Família (ESF), partindo de processos educativos em grupos comunitários pautados pela perspectiva pedagógica freireana: a Educação Popular ${ }^{7}$. O processo investigativo foi conduzido por meio do desvelamento de caminhos nessa experiência, 
o que se justifica no interesse do estudo em explicitar saberes e práticas que sejam efetivamente capazes de agregar novas perspectivas para as realizações educacionais em saúde e SAN promovidas no cotidiano da Atenção Básica, especialmente, em suas iniciativas coletivas e grupais, de modo a contribuir com a qualificação, aprimoramento e, em alguns casos, reorientação dessas práticas, inclusive pela contribuição no fomento ao debate, à formação e à reflexão dos protagonistas dessas ações, quais sejam os trabalhadores, gestores e usuários da ESF.

Nesses termos, esta pesquisa nasceu da inserção de um dos pesquisadores em um Programa de Extensão da UFPB, o qual vem atuando há dez anos em um mesmo território, de maneira articulada à sua Unidade de Saúde da Família (USF), além de outros equipamentos sociais, como Escola Pública, Centro de Referência em Assistência Social (CRAS), Cozinha Comunitária, dentre outros. Sendo assim, sua realização deu-se de maneira articulada às ações extensionistas e à realidade social dinâmica daquele território, valorizando-se, na construção investigativa, a participação ativa dos atores desses equipamentos sociais, como forma de potencializá-los e aprimorar a capacidade de seus processos educacionais em PS e SAN de produzirem conhecimentos úteis à sociedade e processos instituintes de mudanças no contexto da saúde e da pobreza local.

Constitui objetivo do presente artigo desvelar os caminhos de construção de processos educativos para a PS e da SAN no contexto da Atenção Básica. Além disso, contextualizar a origem e os pressupostos que sustentam o Programa de Extensão, ressaltando em que bases se deu sua relação com a comunidade. Levantar aspectos relativos ao funcionamento e organização de processos educativos empreendidos com apoio do Programa de Extensão estudado. Identificar caminhos (potencialidades) e desafios (obstáculos) dos processos educativos estudadas no que tange à PS e à SAN na AB.

\section{MÉTODOS}

O presente trabalho estudou a experiência do Programa de Extensão "Práticas Integrais de Promoção da Saúde e Nutrição na Atenção Básica (PINAB)", vinculado ao Departamento de Promoção da Saúde/Centro de Ciências da Saúde e ao Departamento de Promoção da Saúde/Centro de Ciências Médicas da UFPB. O PINAB é pautado pela Educação Popular e aplicado com práticas educativas empreendidas em grupos comunitários na ESF.

O caminho investigativo foi construído por meio de uma pesquisa qualitativa, envolvendo, conforme fundamentado por Gadamer ${ }^{8}$, a busca de compreensão dos sentidos e, como ressalta Minayo ${ }^{9}$, a valorização dos contextos pesquisados, bem como os significados, valores e as atitudes intervenientes. ${ }^{8,10}$

Sua operacionalização deu-se a partir de uma pesquisa documental. ${ }^{11}$ Houve coleta de dados acerca do funcionamento, histórico, estruturação e pautas do Programa 
de Extensão estudado, centralmente no que tange a suas realizações educacionais no campo da PS e da SAN nas comunidades de sua atuação, sendo então informações levantadas, registradas e organizadas por meio de um roteiro, preenchidas pelos próprios pesquisadores, a partir de seu olhar e do acesso a fontes documentais, sem abordagem a seres humanos.

$\mathrm{Na}$ pesquisa documental, no que se refere à mobilização de dados e informações, considerou-se o período entre agosto de 2007 a dezembro de 2017; tal delimitação foi importante no sentido de enfocar com maior profundidade os processos educativos estudados, considerando, principalmente, o longo tempo no qual o PINAB está em atividades.

Os materiais e documentos utilizados foram os seguintes: atas pedagógicas das reuniões e encontros dos grupos do PINAB (disponíveis no acervo da coordenação do Programa, no Google Drive da conta de e-mail: pinab.ufpb@gmail.com), nas quais são registradas as atividades realizadas, enfatizando-se data, participantes, número de envolvidos, dinâmicas promovidas, temáticas discutidas, local da reunião, questões emergentes e reflexões momentâneas dos facilitadores; relatório semestral de atividades (disponível no blog do PINAB: www.projetopinab.blogspot.com), com consolidação das informações das atas pedagógicas, priorizando informações como atividades realizadas, resultados observados nas ações, relatos individuais, reflexões promovidas, bem como observações, sugestões e perspectivas dos integrantes do Grupo.

Cabe destacar que, embora não constituindo parte do acervo documental estudado, foram consideradas como apoio no processo de análise as produções científicas elaboradas pelos participantes da experiência em período anterior ao estudado, sendo elas o livro "Educação Popular e Nutrição Social: reflexões e vivências com base em uma experiência", no qual se sistematizou a experiência do PINAB desde sua origem, com capítulos enfocando suas diferentes atividades e dimensões, explicitando seus caminhos de construção; e a coletânea, em formato $e-b o o k^{12}$, na qual se encontram reunidos todos os textos científicos e acadêmicos produzidos no âmbito do PINAB no ano de $2014 .{ }^{13}$

Para a sistematização dos resultados, um roteiro foi adotado como instrumento, que veio a ser preenchido pelos pesquisadores, com as seguintes categorias de informações: 1- Identificação (nome ou título) do grupo, processo ou experiência desenvolvida; 2- Descrição do horário, periodicidade e longevidade do grupo, processo ou experiência; 3- Descrição da média de público participante; 4- Descrição qualitativa do perfil dos participantes; 5- Motivos e razões pelos quais surgiu o grupo, processo ou experiência; 6- Motivos e razões pelos quais findou o grupo, processo ou experiência (se for o caso); 7- Temáticas, questões e problemas sobre os quais o grupo, processo ou experiência se debruçou.

$\mathrm{Na}$ etapa de análise, fizemos uma leitura de todas as fontes documentais, considerando-se o foco temporal do estudo e o seu objeto, seguida de uma segunda 
leitura e, posteriormente, a sistematização de categorias emergentes em um quadro que as ressaltassem da seguinte maneira: 1 ) atividades desenvolvidas no que tange às práticas educativas na Atenção Básica; 2) procedimentos metodológicos dessas atividades; 3) princípios orientadores dessas atividades; 4) abordagens e dinâmicas utilizadas; e 5) temáticas trabalhadas e discutidas.

A perspectiva de análise desenvolvida no decorrer desta pesquisa consistiu da dialética. Como afirma Holliday, a concepção metodológica dialética é uma maneira de conceber a realidade, de aproximar-se dela para conhecê-la e de atuar sobre ela para transformá-la. ${ }^{14}$ Assim, podemos considerar a dialética como um modo de analisar a realidade, considerando-a em sua essência contraditória e em permanente transformação. ${ }^{15}$

Para isso, uma análise dialética configura-se em um cuidadoso estudo e debruçase sobre a realidade, tomando como ponto de partida a complexidade a ela inerente, suas várias facetas, contradições, aparências e ilusões, conforme aponta Melo Neto ${ }^{15}$. Optamos pela dialética marxista, a qual parte do real, por meio de movimentos profundos de reflexão direcionados para a revelação da verdade, ou mesmo da elevação crítica da consciência sobre esta realidade. ${ }^{15} \mathrm{~A}$ perspectiva marxista da dialética envolve centralmente a tríade de tese, antítese e síntese (conforme estabelecido por seu antecessor, Hegel), expressas em três movimentos de análise crítica: do real (concreto) para o abstrato; do abstrato para um novo abstrato; e, finalmente, deste novo abstrato para um novo concreto (concreto pensado).

\section{RESULTADOS E DISCUSSÃO}

\section{Origem do PINAB}

Criado em 2007, o Programa de Extensão PINAB foi fundado vinculado ao Departamento de Nutrição do Centro de Ciências da Saúde na UFPB. Ainda caracterizado como projeto, trazia na época o nome de "Práticas Integrais de Promoção de Nutrição na Atenção Básica", carregando em sua denominação todo processo em que os então fundadores almejavam atuar. O processo de fundação do projeto de Extensão surgiu da inquietação de alunos do curso graduação em Nutrição, insatisfeitos com a proposta curricular que o curso oferecia, sendo que esta não contemplava espaços para experiências construtivas em Saúde Coletiva e, mais especificamente, em Educação Popular.

Essa inquietação não partia somente desse grupo de estudantes, mas advinha de grupos de estudantes de outras gerações que também não se conformavam com um currículo acadêmico construído com ênfase na atuação clínica do profissional nutricionista, distante dos problemas sociais que afligiam o estado, haja vista que a Paraíba 
convivia com significativos problemas relacionados à fome, à insegurança alimentar e à miséria naquela época. A busca desse grupo concentrava-se basicamente na procura de alternativas que formassem profissionais para terem uma nutrição integrada com a vida e com os problemas da sociedade, especialmente dos setores menos favorecidos social e economicamente.

Embora já existissem atuações consolidadas na UFPB sob a perspectiva da Educação Popular, com atividades realmente integralizadas e direcionadas para uma atuação humanista e popular, essas frentes eram direcionadas para a atuação dos seus docentes coordenadores e, como não havia docentes de nutrição vinculados a esses projetos, a atuação do aluno de Nutrição pautava-se somente em vivências pontuais.

Mesmo diante de tais empecilhos, diversos estudantes que atuavam no Projeto Educação Popular e Atenção em Saúde da Família (PEPASF) lideraram a construção de um projeto de Extensão em Educação Popular que tivesse a atuação e o saber do nutricionista como foco principal. Todavia, uma das maiores dificuldades era a falta de um docente que assumisse a frente enquanto coordenador. Por isso, a primeira intervenção do grupo foi solicitar a transferência de um estágio que ocorreria no Hospital Universitário Lauro Wanderley (HULW) para uma USF no Bairro Cristo Redentor, que, devido ao sucesso de atuação, posteriormente se mostraria como o local de atuação do projeto que estava em processo de fundação e aprimoramento. Foi ao conhecer uma docente, que também compartilhava de propostas integrais e que ansiava por construir uma experiência de trabalho social a partir da extensão e por ver a materialização dos princípios da SAN na realidade, que o grupo de estudantes teve um ponto importante na largada de construção do projeto junto a uma professora do Departamento de Nutrição da UFPB, a qual foi a primeira coordenadora da experiência.

O primeiro passo para tal ancoragem do projeto foi decidir o local de atuação do mesmo, em que ficou determinado que as atividades iriam ocorrer no Bairro Cristo Redentor, nas comunidades de Jardim Itabaiana, Pedra Branca e Boa Esperança, pois já havia um contato e uma relação com a equipe da USF local, denominada de Vila Saúde. Dando continuidade, foram determinados os processos de operacionalização em que se dariam as práticas e, posteriormente, o grupo passou por uma vivência de seis meses inserido dentro do futuro local de atuação, conhecendo os populares, as famílias, as estruturas e condições de moradia e trabalho. O local de atuação, então, dar-se-ia nas comunidades de Jardim Itabaiana I, Jardim Itabaiana II, Pedra Branca I e Pedra Branca II (essa comunidade atendia o território da comunidade Boa Esperança). E foi a partir dessa vivência que o grupo pôde, além de expor os propósitos do que seria o projeto, escutar as demandas dos profissionais de saúde, no sentido de buscar convergências de ações.

Depois de tais direcionamentos, a seleção foi realizada para ocupação inicial de 20 vagas e, para a surpresa dos organizadores, as inscrições superaram mais de 100 
candidatos, o que mostrou o anseio da comunidade acadêmica do curso de Nutrição por uma frente que realizasse atividades que realmente valorizassem a integralidade que $o$ conhecimento do nutricionista pode oferecer às práticas sociais.

Funcionamento e organização dos processos educativos no PINAB

Durante todo o funcionamento do programa, o PINAB realiza processos educativos diante de várias frentes, as quais são chamadas de Grupos Operativos, já que coletivos delimitados de extensionistas operacionalizam atividades em diferentes áreas de atuação, de forma educativa, lúdica, reflexiva e eficaz.

Dentro dos dez anos de funcionamento, o programa já contou com 13 grupos operativos, ambos com frente de atuação inserida dentro de espaços da comunidade, como na USF Vila Saúde, na Escola Municipal de Ensino Fundamental Augusto dos Anjos e em outros espaços onde os moradores mantinham frequência por determinados motivos cotidianos, fosse acompanhamento da situação da saúde ou o saque mensal do auxílio concedido pelo Programa Bolsa Família.

Grupo de Gestantes

Esse grupo partiu de um desejo da própria equipe de saúde em cuidar das gestantes, não somente com um olhar sistemático e puramente biológico, mas de uma maneira integral, a fim de criar alternativas que estimulassem iniciativas próprias em busca do bem-estar, dessa forma, qualificando ainda mais o acompanhamento do pré-natal.

O Grupo priorizava uma atuação que abrisse espaços para que as gestantes trouxessem os seus contextos sociais, emocionais e culturais para a roda, protagonizando um processo de cuidado em saúde que se dava de maneira coletiva entre elas.

Esteve em funcionamento de 2007 a 2011, através de encontros quinzenais onde se compartilhavam os saberes e repres entações relacionados à alimentação e nutrição: qual a relação das pessoas com a alimentação, significados e importância da alimentação. Além disso, nas diversas reuniões, emergiram temas das inquietações e dos anseios das gestantes, tais como: hora do parto - quando elas ressaltaram cada momento e o que fazer, a fim de ter um parto tranquilo e seguro; direitos das gestantes; sexualidade; cuidados com o bebê - quando as mães esclareceram suas dúvidas e levaram suas experiências; alimentação das gestantes - quando discutimos com elas sobre a promoção da alimentação saudável; saúde bucal e sua importância para o bebê e os procedimentos considerados corretos; alimentação do bebê - quando foi abordado desde o início da amamentação até o desmame, elucidando as dificuldades e as potencialidades de cada um. 
Em alguns encontros, eram realizadas outras dinâmicas, como relaxamento, alongamento, autocuidado corporal, dança, dentre outras. Ressalta-se a importância do grupo na mudança comunitária sobre o olhar do gestar, do cuidado pessoal no período de gestação e na autonomia do ser mãe.

Grupo Escola

Nesse grupo, o projeto participou de atividades que traziam a proposta de trabalhar com os alunos caminhos de aprendizagem para uma alimentação adequada e saudável, além de gerar um espaço integração entre o PINAB, a USF Vila Saúde e a Escola Municipal de Ensino Fundamental Augusto dos Anjos, que se tratando do espaço físico, eram separados apenas por um muro. Todavia, mesmo com essa proximidade, as atividades de promoção da saúde que eram realizadas pela USF não adentravam os muros da escola, o que era um tanto desfavorável, pois o contato direto com as crianças e os jovens que estudavam na escola serviria de disseminação eficaz das propostas de SAN que o projeto trazia. Com o estabelecimento da parceria com a direção da escola, algumas intervenções foram feitas em sala de aula e com as merendeiras, os professores e as professoras, em uma ação que discutisse sobre saúde de forma ativa, criativa, dinâmica, lúdica e crítica. ${ }^{16}$

As atividades aconteciam primeiramente dentro da sala de aula, com dinâmicas, rodas de conversa e brincadeiras que permitissem aos alunos um pensamento crítico em relação à alimentação saudável e à SAN, tanto pessoal quanto familiar. Tendo em vista demandas pedagógicas diferenciadas para crianças e adolescentes, o Programa manteve, em diferentes momentos de seu percurso histórico, dois grupos operativos na Escola, sendo um no turno da manhã e outro na tarde, dedicando interações específicas com cada um destes coletivos de escolares.

Posteriormente, outras atividades foram acrescentadas às atividades do grupo operativo, como mostras e gincanas que estimulassem uma competição saudável, propiciando, dessa forma, um envolvimento maior tanto dos estudantes como de todo corpo escolar, além de outras atividades voltadas para os direitos dos usuários diante do Sistema Único de Saúde (SUS). Neste Grupo, os extensionistas do PINAB promoveram, também, momentos de formação com os professores da escola, envolvendo como tema central saberes e práticas para a promoção da alimentação saudável no cotidiano escolar.

Ao longo dos anos, as ações priorizaram gerar movimentos para sensibilizar alunos, professores e direção a transformar a escola em um lugar para práticas saudáveis de convivência, desenvolvimento psíquico-motor, aprendizado de todos e, assim, torná-la um centro de promoção de saúde local. Para isso, criaram-se metodologias compromissadas com a formação de estudantes participativos e de professores sensibilizados acerca do seu papel como facilitadores na construção de conhecimentos. 
O impacto do grupo operativo foi significativo, de modo que os extensionistas foram convidados enquanto projeto para integrarem o planejamento letivo das atividades da escola, o que mostrou o quanto as atividades educativas de promoção da SAN se mostravam eficazes diante da comunidade escolar.

Grupo Programa Bolsa Família

Outra ação que começamos a desenvolver desde o início, em 2007, foi o Grupo Programa Bolsa Família (PBF), destinado a acompanhar as ações do PBF no território e provocar ações educacionais problematizadoras com os servidores que o executavam e a população beneficiária. As atividades davam-se tanto através de espaços educacionais, de oficinas e de cursos, quanto de acompanhamento de ações, como os mutirões de verificação das condicionalidades de saúde do programa (peso, idade, vacina).

Na época em que iniciamos o PINAB, o PBF já estava em evidência no Brasil, no âmbito da política pública de promoção da SAN e do Direito Humano à Alimentação Adequada e Saudável (DHAAS). Porém, tanto os estudantes de Nutrição quanto a professora coordenadora tinham críticas quanto ao PBF, particularmente no campo da saúde, no tocante à necessidade de o Programa ter uma atuação mais abrangente e estruturante, que não se limitasse apenas à verificação das vacinas, do peso e da altura das crianças cujas famílias eram beneficiárias desse programa. A saúde poderia proporcionar muito mais no contexto do PBF, por exemplo, fazer questionamentos sobre as condições, as situações-limite e as possibilidades de se proporcionar uma alimentação saudável às famílias beneficiadas pelo PBF, na perspectiva de conceber os beneficiários como sujeitos de direitos, inclusive do direito a uma alimentação adequada.

Mas havia fragilidades nessa direção, de modo que esse Grupo foi criado para provocar conversas, discussões e reflexões com a equipe de Saúde, no sentido de ampliar seu olhar acerca do papel do PBF na ESF e no território.

Assim, realizou-se um curso de formação com os Agentes Comunitários de Saúde (ACS) para o trabalho diante da perspectiva teórica que o PBF trazia, intitulado "O Agente Comunitário de Saúde e o Programa Bolsa Família". O mesmo foi desenvolvido utilizandose de recursos como dinâmicas de grupo, músicas, vídeos e textos, e foi realizado em 5 oficinas, com os seguintes temas: Fome Zero e programas complementares ao PBF; conceito, condicionalidades, critérios de inclusão e benefícios do PBF; DHAAS e SAN; o PBF no cenário da USF Vila Saúde; e, por fim, Sistema de Vigilância Alimentar e Nutricional (SISVAN). ${ }^{17}$

Em outras palavras, o trabalho desse grupo foi principalmente dialogar com os profissionais de saúde sobre o PBF, a SAN e do DHAAS. Aprendemos no caminho que não adiantava chegarmos aos profissionais e confrontá-los com a forma de trabalho 
deles, "obrigando-os" a pautar a SAN em suas ações. É necessário colocarmo-nos no lugar dos profissionais de saúde, como os ACS, médicos e enfermeiras, e construirmos possibilidades com eles, e não somente para eles.

A partir dessa metodologia, pudemos introduzir e sintetizar com os profissionais de saúde as ideias a respeito da SAN. Com isso, pudemos fortalecer o aprendizado e a conscientização sobre a SAN, munindo os trabalhadores da USF de ferramentas capazes de oportunizar um conhecimento relevante sobre o PBF e a concepção de SAN.

\section{Grupo de Mobilização Popular}

Esse grupo nasceu da inquietação da equipe do PINAB em possibilitar espaços para conhecer e valorizar iniciativas dos grupos sociais daquele território, através do diálogo direto com as pessoas e suas referências populares, afetando-se somente das "quatro paredes" das instituições públicas locais, como a USF e a escola. Essa ação teve início a partir da mobilização popular pela criação do Conselho Local de Saúde (CLS).

Com o Grupo de Mobilização Popular (MP), percebeu-se ser possível criar espaços permanentes de diálogos entre os grupos sociais territorializados e a equipe de saúde da família. A discussão de assuntos da própria realidade e vivências pessoais, através da troca de saberes a partir de experiências, não somente é possível como pode permitir uma interação transformadora entre população e trabalhadores de saúde, construindo gradativamente caminhos possíveis para a melhoria de vida daquele povo. Participando ativamente do grupo, os estudantes do PINAB puderam refletir que aquele espaço não era apenas de reclamações de moradores da comunidade em relação ao serviço, mas, sim, de aprendizados a partir de situações do cotidiano que são impostas no transcorrer de cada dia. ${ }^{16}$

O Grupo MP articulou ações educativas para o fomento de espaços de debate sobre controle social em saúde na área adscrita à USF. Para tanto, apoiou o desenvolvimento de reuniões com usuários, gestores e trabalhadores da USF. Foi a partir dessa integração que se criou a experiência do Espaço de Diálogo, através da qual se constituiu e se desenvolveu o CLS daquele território, ocorrendo mensalmente através de reuniões entre a equipe de saúde e os sujeitos da comunidade, mesmo que a gestão do SUS não tivesse apoiado (na época) sua instituição formal.

Assim, passaram a romper preconceitos contra as instâncias de participação popular e de controle social em saúde, para que os estudantes percebessem os jogos de interesses, os conflitos e as tensões nos relacionamentos entre os representantes diversos da comunidade e a equipe de saúde. Portanto, constatamos que o conflito fazia parte do processo de participar em saúde e que ele também constituía momentos de diálogo e de aprendizado conjunto. Em muitas ocasiões, nas discussões do Espaço de Diálogo, os tensionamentos não eram feitos somente para desgastar, pois resultavam 
de um processo autêntico de conhecimento e de encontro entre culturas e visões de mundo distintas. Em muitos casos, dialogar implica tensionar, até que os diferentes atores dialogantes passem a se conhecer melhor, a se entender uns com os outros e a aceitar verdadeiramente os aprendizados estabelecidos naquela relação específica.

Desde então, até o ano de 2012, o Grupo MP articulou ações educativas para o fomento de espaços de debate sobre controle social em saúde na área adscrita à USF.

Grupo Saúde na Comunidade

Esse grupo foi idealizado na intenção de ser criar um espaço de Educação Popular que dialogasse com os sujeitos e os cenários inseridos no cotidiano mais íntimo da comunidade, particularmente, a Boa Esperança e a Pedra Branca, onde poucos setores institucionais entram, seja por medo da violência, seja por preconceito, devido às precárias condições de infraestrutura no local. Surgiu em 2009, a partir do grupo de mulheres, como uma forma de ocupar espaços de discussão comunitária de maneira mais ativa dentro da comunidade.

A base de inspiração do grupo era o cotidiano dos grupos sociais comunitários e as experiências de vida das pessoas, quando se conversava sobre saúde e alimentação. O grupo foi cumprindo a sua função de refletir tanto com elas quanto com os estudantes sobre o papel do profissional nutricionista, que pode e deve atuar em um espaço de pobreza, miséria, limites e contradições, para que possa ser um parceiro dessa população, no sentido de encontrar saídas para suas dificuldades e de realizar o seu DHAAS.

No Grupo Saúde na Comunidade (SC), a PS é trabalhada de forma participativa. Partindo da abordagem das histórias de vida, discutem-se com os indivíduos aspectos e reflexões sobre a participação popular de forma mais consistente nos espaços comunitários, construindo uma visão crítica da saúde. Os temas eram escolhidos pelas pessoas da comunidade, a maioria, mulheres. A partir desses encontros, fomos desmistificando com elas a alimentação saudável e o papel do nutricionista, dado que muitas mostravam resistência em relação ao nutricionista, porque achavam que ele era apenas para ricos e indicava dietas caras.

O grupo estabeleceu como prioridade desenvolver atividades com ênfase ativa, o que se dava através de diferentes formas de dinâmica para envolver e mobilizar os participantes. Dentre as metodologias utilizadas, destacaram-se dinâmicas integrativas, exercícios de autocuidado, esquetes teatrais, produção de peças de artesanatos, escuta e canto de músicas, produção de desenhos, exibição de vídeos, produção de mural informativo, compartilhamento de receitas culinárias com foco no aproveitamento integral dos alimentos, além de viagens com visitas a outras cidades, a fim de propiciar ao grupo o contato com outras experiências exitosas de PS. 
No decorrer deste grupo, percebemos, dentre suas potencialidades, o fortalecimento e estreitamento do vínculo do grupo com algumas lideranças comunitárias da área. Assim, o grupo passou a constituir um ponto de encontro, onde conversávamos sobre alimentação abertamente, quebrando preconceitos e buscando caminhos para essas mulheres concretizarem o seu direito à alimentação a partir de suas próprias possibilidades; sem, no entanto, deixar de reconhecer os limites econômicos e também incentivando para que rompessem esses limites e buscassem ser mais.

Grupo de Idosos

Em 2013, em um contexto da reorientação do desenho do PINAB, a equipe de extensionistas decidiu enfatizar a perspectiva de atuar em uma instituição de longa permanência de idosos da comunidade, a Associação Promocional do Ancião (ASPAN), na qual, embora a houvéssemos há muito mapeado, não tínhamos atuado até então. Assim, o PINAB passou a atuar com ações desenvolvidas quinzenalmente aos sábados pela manhã na ASPAN.

Durante o desenvolvimento de suas atividades, os extensionistas articulam o compartilhar de histórias, emitindo respeito, afeto humano e cuidado ampliado, traduzindo a vivência da amorosidade. Isso se dá, principalmente, através de rodas de conversas, articuladas no próprio espaço da instituição. Para a realização das atividades são adotadas ferramentas metodológicas que se adequem às limitações físicas de algumas das pessoas, mas que, ao mesmo tempo, motivem a participação e estimulem a superação. Um exemplo têm sido as atividades de pintura e estímulo à criatividade deste público.

Dentre outras metodologias, esse grupo vem elaborando e implementando a linguagem do Palhaço Cuidador, a partir de proposta pedagógica elaborada pelos professores coordenadores do projeto PalhaSUS da UFPB. Com ela se pode aprimorar a comunicação com os idosos e fazer dinâmicas e atividades para o cuidado integral em saúde com esse público. Os palhaços que atuam nesse projeto são estudantes do PINAB que foram formados e capacitados para isso pelo Projeto PalhaSUS, em uma parceria estabelecida com essa ação de extensão. Assim, o propósito maior é de promover o cuidado e a atenção em saúde, através de um contato, um abraço, um carinho, além de despertar nos extensionistas sentimentos que fortalecem e renovam valores como a solidariedade e a amorosidade.

A linguagem do palhaço contribuiu no autocuidado, pois não era fácil para os extensionistas lidarem com suas próprias emoções ao se depararem com vários idosos em situação até de abandono, que tiveram uma história e hoje ficam à mercê do tempo. Além disso, pudemos abordar os talentos dos idosos e incentivá-los a desenvolverem os temas de que eles gostavam, como música, dança e artes. A partir dessa perspectiva, 
pudemos desviar o olhar dos próprios idosos de um problema do processo saúde-doença para a vida. Pois, embora a instituição fornecesse saúde, higiene e bem-estar, os idosos sofriam com a monotonia do cotidiano e, com esse trabalho, pudemos gerar mais vida e qualidade, através da ideia principal de que eles poderiam fazer as atividades não só quando estávamos lá, mas também na nossa ausência.

Grupo Saúde do Trabalhador

O Grupo Saúde do Trabalhador (ST) surgiu no ano de 2013, a partir da parceria do projeto PINAB com o Programa de Educação Popular, Saúde, Cultura e Trabalho. Dentro de uma das demandas deste programa, encontrava-se a realização de uma pesquisa científica que possuía como referencial teórico questões emergentes da interface entre saúde e trabalho em categorias de trabalhadores significativas no território de atuação, além de elucidar dispositivos teórico-metodológicos de diálogo entre Educação Popular e Ergologia, particularmente com os ACS de uma USF próxima à comunidade Boa Esperança, a Unindo Vidas. Além disso, o ST envolveu também os professores da escola do território de ação do PINAB.

Este grupo operativo passou a ser desenvolvido no turno da tarde, às sextasfeiras, reunindo-se com os ACS quinzenalmente e com os professores de forma mensal, objetivando analisar questões emergentes da interface entre saúde e trabalho no cotidiano desses trabalhadores, tendo como metodologia a seguinte estruturação: círculos de cultura capazes de evidenciar as situações-limite e construir os inéditos-viáveis para os desafios expostos pelos trabalhadores no que tange à interface saúde e trabalho; sistematização de produtos (sociais e acadêmicos) que revelem as potencialidades e dificuldades encontradas, bem como evidenciem estratégias de superação possíveis.

Além disso, o grupo promoveu momentos de cuidado integral dos próprios trabalhadores - professores e ACS -, conforme demandados pelos mesmos, mediante seu cotidiano exaustivo de trabalho e dedicação em seus espaços de atuação. Essa estratégia acabou não dando certo na USF Vila Saúde. Logo tivemos que procurar outra USF, passando o grupo a funcionar no Unindo Vidas. Assim, a atividade possibilitava ao profissional de saúde parar um pouco o trabalho, de modo a utilizar esse tempo para refletir como ele estava trabalhando e se alguma atividade estaria prejudicando a saúde dele. A partir daí, procuramos alguns profissionais, principalmente os ACS, para realizar essas atividades. Inicialmente, o grupo começou com sete profissionais. Uma das maiores dificuldades foi fazer com que os profissionais de saúde valorizassem as atividades de reflexão do trabalho e da saúde, pois muitos podiam preferir utilizar o tempo para descansar ou fazer outra atividade. Um dos maiores avanços foi quebrar essa barreira inicial com o grupo. Pelo processo que foi desenvolvido, os próprios profissionais passaram a valorizar o momento. Outro desafio era fazer com que o profissional não se 
visse em um local de trabalho, assim tentávamos mudar um pouco a decoração da sala onde as atividades eram realizadas para facilitar a reflexão.

Um dos pontos mais positivos foi conhecer e aprender um pouco mais sobre a rotina de trabalho do agente comunitário de saúde e poder ajudá-lo a melhorar o processo de trabalho que é contínuo e diário. Pois, diferentemente de outros profissionais de saúde, que estão em serviço quando dentro da USF, o ACS mora na comunidade e, tendo um maior contato com ela, é sempre procurado quanto a assuntos de saúde. A título de exemplo, quando alguém passa mal de madrugada, as pessoas vão à casa do ACS. Além disso, quando há problemas entre os profissionais de saúde e o usuário, quem medeia, muitas vezes, é o ACS. A partir desse conhecimento da rotina do profissional e das dificuldades que eles passavam, nosso trabalho foi facilitado, abrindo-nos um novo olhar para ajudá-los no dia a dia. Quanto aos professores, o desafio era conseguir realizar as atividades, devido aos horários diferentes de cada um.

\section{Grupo Horta Popular Boa Esperança}

Desde 2013, o PINAB vem atuando participativa e radicalmente junto com os grupos sociais comunitários. Com a criação do grupo operativo Horta Boa Esperança não foi diferente. O mesmo foi fruto da mobilização a partir da ideia de uma líder comunitária, a qual tinha o intuito de criar estratégias concretas de produção de alimentos de forma sustentável e solidária naquela região para mobilizar efetivamente as pessoas dos grupos sociais comunitários em torno das ações do Programa, além de possibilitar impactos mais concretos na situação de fome e pobreza vivenciada por algumas famílias no local.

Em seu início, o grupo investiu em reuniões internas de formação e planejamento, objetivando-se a enriquecer os conceitos e conhecimentos acerca de ações de SAN e das diretrizes de suas políticas públicas. Debruçou-se também sobre o contexto alimentar e nutricional comunitário, suas relações intersetoriais e pesquisas relevantes dentro do tema através de leituras, discussões e a utilização de vídeos ("Por uma vida melhor" e "Garapa"), além de analisar as concepções de soberania alimentar e insegurança alimentar, bem como os fatores relacionados e as medidas para superá-la.

Inicialmente, houve conversas com líderes comunitários, comerciantes locais e moradores da área próxima à nascente do rio, para explicar a proposta, ouvir sugestões e, fundamentalmente, verificar a aprovação deles para a construção da horta. Como resultado, saiu fortalecida a ideia da horta, para cuja construção os moradores disponibilizaram lugares protegidos, na área do leito do rio e ofereceram espaço e alguma infraestrutura para a realização de reuniões. Em um segundo passo, começamos a visitar semanalmente o local, mobilizando os grupos sociais territorializados por meio de cortejos com palhaços cuidadores, os quais percorriam o território, desde sua entrada até as margens do rio (onde seria a horta), distribuindo convites, explicando as intenções 
e propostas e convocando as pessoas para participar.

Nas semanas subsequentes, enquanto uma parte dos extensionistas continuava o processo de mobilização junto às famílias e casas, os outros reuniam-se com as pessoas da comunidade que começavam a se fazer presentes e promoviam, assim, a limpeza do local (com retirada de materiais não orgânicos e do excesso de lixo depositado na área de vegetação rasteira).

Posteriormente, abrimos os primeiros canteiros e fizemos os plantios, colocando mudas de árvores sobretudo nas margens da nascente do rio, visando revitalizá-lo, primeiro (nos canteiros) plantas medicinais, alface e coentro. Enquanto isso, abriu-se espaço para as pessoas da comunidade levarem também suas mudas e plantas para agregar no espaço da horta. Nesse processo, os próprios moradores vão aprendendo a semear e cultivar, bem como cuidar dos canteiros.

No final de cada sessão de atividades, é realizada uma roda de conversa pelo grupo Saúde na Comunidade, quando se convidam as pessoas que estão na construção da horta para discutir sobre assuntos de seu interesse, sobretudo os relacionados às situações de saúde e de insegurança alimentar daquele local, bem como aspectos relacionados ao cotidiano das famílias. Em uma dessas reuniões, decidiu-se coletivamente qual seria o nome da Horta: Horta Popular Boa Esperança.

A partir dessa experiência, conseguimos fortalecer o diálogo com as pessoas e grupos sociais da comunidade. Pudemos identificar que pessoas naquele território eram efetivamente parceiras no sentido de fazer trabalhos sociais, e não apenas no sentido de aparecer para fazer discurso e ocupar cargos. Além disso, pudemos ter a noção mais apurada de que estávamos construindo outra nutrição, a partir do próprio PINAB.

O PINAB estava gerando, junto com sujeitos daquele território, outras abordagens teóricas e práticas em Nutrição. E essas abordagens ganhavam sentido a partir do momento em que nós desconstruíamos o enfoque tradicional da nutrição para construir uma nutrição aplicada à vida e integrada àquelas pessoas, comprometidas com a construção de caminhos para sua emancipação. Logo abaixo, seguem três registos importantes nesse processo. O primeiro com moradores da comunidade levando para suas casas as primeiras hortaliças; o segundo e o terceiro, com uma visão geral da organização da Horta Popular em janeiro de 2015, já tendo muitas variedades sendo plantadas e colhidas.

Grupo de Caminhada

O bem-estar pode ser definido como um conjunto de práticas que englobam uma boa nutrição, atividade física, bons relacionamentos interpessoais, familiares e sociais, além de controle do estresse. Adotando esse ponto de vista, podem-se buscar meios acessíveis de englobar todas essas necessidades em simples atividades, sendo assim 
desenvolvido o Grupo Caminhada. Através de uma caminhada ao fim tarde, o contato entre as mulheres das comunidades pode ser estreitado, favorecendo um momento para a prática de exercícios físicos, de boas conversas e de bom funcionamento corporal.

Originado a partir de um grupo já existente, voltado para o entrosamento e a melhoria pessoal na qualidade de vida de hipertensos e diabéticos, a proposta surgiu da própria equipe, a partir da necessidade de incluir esses idosos em atividades físicas adequadas para sua situação de saúde e idade. O PINAB apoiava o Grupo levando aos encontros semanais, que aconteciam nas segundas-feiras ao fim da tarde, dinâmicas e temas sobre saúde para serem discutidos, alimentação e melhoria da qualidade de vida. Os extensionistas também pesquisavam e levavam propostas de exercícios que eram possíveis de se realizarem junto às participantes do momento e que eram conduzidos com a ajuda de um educador físico.

No segundo semestre do 2016, o Grupo Caminhada sofreu algumas modificações em sua estrutura dentro do programa PINAB. O programa decidiu incluir em suas atividades visitas domiciliares a membros comunitários que se afastaram das atividades do grupo ou membros que, segundo as ACS, poderiam se beneficiar com as atividades realizadas no Grupo Caminhada. Dessa forma, nas segundas-feiras, alguns extensionistas auxiliavam na caminhada propriamente dita e, nas sextas-feiras, outro grupo de extensionistas realizava, com o acompanhamento de uma ACS, as visitas domiciliares a pessoas com potencial de participarem dos encontros semanais.

Grupo Brincando com a Mente

O Grupo Brincando com a Mente desenvolveu diversas atividades voltadas para a saúde mental de diversos usuários da USF Vila Saúde que, semanalmente, se deslocam para a USF em busca da atualização de receitas para a medicação prescrita. O foco do grupo é criar um espaço lúdico e acolhedor para esses usuários como forma de reduzir o uso de medicamentos psicotrópicos, como também buscar, através do contato direto com os envolvidos, melhorias na qualidade de vida do meio onde estão inseridos.

O grupo realiza reuniões semanais com trabalhadores da USF, sua equipe multiprofissional e seus extensionistas, para a formação de estratégias que culminem em bem-estar e promoção de saúde dos seus participantes, que já configuram cerca de 30 pessoas, incluindo cuidadores e familiares.

Já os encontros com os moradores da comunidade trazem reflexões sobre o processo saúde-doença e a delicadeza do cuidado em saúde mental, sendo realizados uma vez ao mês, pondo em prática as discussões e reflexões realizadas nas reuniões semanais. Rodas de conversa, dinâmicas, danças, alongamentos e oficinais são realizados. Essas atividades propiciam uma maior aproximação com os usuários e entre eles mesmos, trabalhando as experiências vividas por cada um deles, expondo questões que lhes causam 
estresse, fazendo-os não se sentirem sós ao passarem por certas dores e dificuldades e permitindo-lhes dividirem seus pesos e encontrarem parcerias dentro do grupo.

Tendo em vista o depoimento dos extensionistas sobre suas experiências no grupo, percebe-se o quão transformador o mesmo pode ser para além de seus usuários, ao realizar mudanças de paradigmas e formação de um pensamento mais humanizado. Os extensionistas destacam a versatilidade que os integrantes do grupo devem ter ao trabalhar nele, pois estão propensos a se deparar com momentos muito delicados que, algumas vezes, afetam o íntimo desses usuários. Portanto, é preciso saber trabalhar a recuperação da autoestima deles, muitas vezes baixa, sendo o grupo um local onde têm apoio para se sentirem melhor.

Fórum Intersetorial de Promoção da SAN

O Fórum de SAN é uma iniciativa do programa de extensão que visa, em conjunto com os equipamentos de promoção social e de saúde, desenvolver atividades que possam propagar e desenvolver a SAN para os usuários que estão localizados na comunidade do Cristo. É articulado com equipamentos, tais como o CRAS, Cozinha Comunitária, Escola Augusto dos Anjos, Empresa Paraibana de Abastecimento e Serviços Agrícolas (EMPASA), ASPAN e alguns outros, nos quais o Fórum vem ganhando espaço nas discussões e realizações de atividades diversas para a comunidade.

O grupo realiza encontros semanais, com alternância de locais e propostas de atuação, buscando trabalhar a temática no ponto de vista teórico, sobre em que consiste a SAN, e prático, realizando intervenções nos locais de atuação desses equipamentos com atividades lúdicas ou de planejamento. Desse modo, o grupo trabalha com as lideranças e representações dessas entidades de forma participativa na busca de mecanismos por melhores condições de alimentação e vida.

A intersetorialidade necessária para as ações do grupo apresenta-se, às vezes, como uma dificuldade. Dificuldade, esta, relacionada primeiro aos próprios desafios da operacionalização e da implementação das políticas públicas nas áreas da PS e da SAN em contextos de vulnerabilidade social. Convive-se muito com impasses, sofrimentos e situações concretas de alienação dos direitos sociais e humanos. Tal situação acarreta, em muitas ocasiões, cansaço por parte dos profissionais, pois se avolumam as necessidades de empenho e de dedicação no cotidiano de trabalho.

Em segundo lugar, por existir uma fragilidade no que tange aos profissionais pouco estarem habituados a uma cultura de trabalho interprofissional, engendrando seus processos de trabalho de modo convergente com os de outros profissionais e de outros serviços.

Há ainda outro obstáculo relacionado à própria dinâmica do grupo, que envolve os equipamentos e mobilização, ao se trabalhar com algo mais ousado do que o que 
se tinha trabalhado antes. Temos dificuldade para que os estudantes envolvidos no grupo assumam um protagonismo presente em outras iniciativas do PINAB, acarretando uma centralização dos esforços na coordenadora do grupo, o que gera não só uma dependência nos estudantes, mas também nos demais equipamentos.

O grupo tem como resultado ser um grande disparador de processos, como, por exemplo, a cozinha comunitária com a USF Unindo Vidas, onde uma agente da mesma sugeriu que o grupo de idosos retomasse e reavivasse a horta que lá se encontra, servindo como atividade aliada ao grupo de idosos da unidade. Também deve-se valorizar a integração do ensino e extensão, tendo envolvimento dos estagiários de nutrição com o grupo.

Mesmo apresentando-se como um grupo em estágio inicial, é possível perceber a potencialidade de seus mecanismos. O grupo deve continuar mobilizando os setores com o intuito de enfrentar a problemática da sua própria dinâmica de atuação, mas tudo isso para que se possa gerar demandas e novas propostas de articulação entre os setores presentes no mesmo.

Grupo Horta no Vila

Haja vista que ainda é expressivo o número de famílias em situação de fome, vulnerabilidade social e pobreza, para as quais caminhos sustentáveis e autônomos para realização da alimentação como direito humano se revelam fundamentais, ${ }^{18}$ a horta comunitária, criada nas dependências do espaço da USF Vila Saúde, configura-se como mais uma opção de acesso comunitário a alimentos com poder nutritivo e medicinal. Além disso, configura-se também como uma opção promissora e inteligente para aproveitamento de espaços ociosos em comunidades e residências.

Enxergou-se na fitoterapia um propósito importante para a inserção da horta na unidade, qual seja a promoção do uso de plantas medicinais como coadjuvantes do tratamento clínico como uma prática alternativa ou complementar ao tratamento de doenças, reduzind o o uso excessivo de medicamentos alopáticos. Em 2016, o Horta no Vila desenvolveu diversos encontros para manutenção e aprimoramento da horta construída dentro do espaço da USF Vila Saúde e assumiu o desafio de criar pequenas hortas, com materiais alternativos, nas residências dos moradores da comunidade que despertaram interesse em otimizar e reaproveitar espaços em suas próprias casas. Dessa maneira, o grupo tem como finalidade criar um espaço que sirva como elo entre a comunidade e o meio acadêmico no conhecimento de plantas e alimentos que propiciam uma qualidade de vida melhor com baixo custo e compromisso coletivo.

A plantação dentro da unidade também estimula os moradores a realizarem o plantio de alimentos em casa. Por se tratar de um espaço pequeno, público e ocioso, os extensionistas são provocados a buscar e criar formas alternativas de plantio, 
aproveitando o máximo de espaço. Assim, tem como função principal ser um ponto de encontro para atividades pedagógicas, gerando reflexões entre os estudantes e moradores, por exemplo, sobre o aproveitamento de espaços ociosos em suas moradias.

Dentro desse ideário, visamos recriar padrões encontrados na natureza para a produção de alimentos, no nosso caso, no meio urbano, caracterizando nosso local como uma horta-urbana. Os recursos para formação desses espaços partiram do reaproveitamento de materiais descartados e em desuso, possibilitando a construção de canteiros, usando pneus, sistema de irrigação econômico através de gotejamento com pallets, baldes, mangueiras e cotonetes, hortas suspensas com garrafas PET e uma composteira.

Dado o interesse de alguns moradores em formar hortas em suas casas, os integrantes da horta iniciaram um novo caminho. Com a horta na USF bem consolidada, despertou-se um desejo de expansão: passar a formar novas hortas nas casas dos moradores, replicando as técnicas de plantio usadas na unidade e trabalhando ao máximo o aproveitamento de espaços ociosos.

Como a horta não possui muito espaço, os extensionistas são provocados a buscar e criar formas alternativas de plantio, aproveitando o máximo de espaço e fazendo com que os moradores reflitam sobre o aproveitamento de espaços ociosos também em suas moradias. Vale ressaltar que a montagem dessas hortas no âmbito individual, na casa dos moradores, não exclui o âmbito coletivo do grupo, de forma que essas iniciativas se estruturam e se organizam pelo grupo para atender a demandas individuais. Por exemplo, se um morador deseja fazer um novo tipo de plantio em sua casa, pensamos juntos, vemos suas potencialidades e mobilizamo-nos para realizar essa ação.

Tendo em vista as produções que o grupo conseguiu realizar, decidimos realizar a montagem de uma feira orgânica. Nela, seriam vendidos os produtos produzidos pelo grupo. Hoje em dia, há uma feira que lá surgiu por iniciativa de um dos membros do grupo, mas que ainda não se configura como uma feira orgânica. Com essa ação, pudemos perceber a diferença entre as pessoas no trabalho em grupo, o que nos exige a paciência pedagógica e nos faz entender que as pessoas possuem ritmos e dinâmicas diferentes, de maneira que devemos nos reorganizar para formar o ritmo coletivo. Neste caso em específico, discussões ou desavenças poderiam ter sido geradas, mas o caminho optado foi o de buscar, dentro daquilo que já estava sendo iniciado, de que forma poderíamos ajudar os que já participavam daquela feira a certificar seus produtos como orgânicos.

Durante a formação da horta, contamos com a presença de alguns trabalhadores que foram fundamentais para sua formação, mas, atualmente, temos alguma dificuldade de integração com seus trabalhadores, que atuam, em alguns momentos, como agentes desmobilizadores da horta.

A horta tem se mostrado uma potente ferramenta de abordagem da Educação Popular, enquanto se trabalha uma relação direta com a natureza, desenvolvendo 
temáticas sobre saúde e SAN, trazendo as experiências e compreensões de mundo de cada um dos participantes do grupo em suas atividades, valorizando o saber popular dentro de uma prática que vem sendo esquecida na zona urbana e fazendo, assim, um resgate cultural da prática junto à emancipação daqueles que a praticam.

Algumas reflexões

As propostas dos processos educativos que o PINAB realizou desde sua fundação geraram frutos de mudanças consideráveis no cotidiano dos moradores das comunidades em que o programa está inserido. A busca por melhorias no contexto de vida social e das práticas de saúde coletiva configuraram-se como importante caminho no desvelamento de uma promoção da saúde que veja o indivíduo não somente um como cliente, mas como uma pessoa que carrega experiências e inquietações, além da sabedoria adquirida no espaço em que viveu.

A inserção de processos educativos de PS e de nutrição dentro de uma zona de vulnerabilidade social revelou-se uma proposta ousada que, posteriormente, mostrouse eficaz tanto na formação dos estudantes envolvidos, como também na qualidade de vida dos moradores, que, desde então, se viram acolhidos e mais próximos do cuidado e a da atenção de profissionais que valorizam suas experiências e conhecimentos.

Notavelmente, no início de cada grupo, após o período de adaptação e planejamento, os populares mostravam-se animados, pois se viam inseridos em espaços preparados para atender suas necessidades emocionais e estruturais, espaços de diálogo, de escuta, de troca de saberes. Isso fazia com que os grupos sofressem uma injeção de ânimo e as atividades ocorressem da forma planejada, havendo um real envolvimento do público-alvo.

Enquanto diversos fatores contribuem diariamente para solidificação de ações voltadas para a Educação Popular, outras, porém, vão de encontro a essas, podendo citar: indisponibilidade de profissionais que compõem a equipe da USF, falta de extensionistas em horários propícios para a realização de atividades de PS e da SAN, falta de contínuo apoio de líderes comunitários, rotatividade do quadro social de extensionistas no PINAB e necessidade constante de apoio comunitário para atividades que exigem manutenção contínua, como a Horta no Vila.

\section{CONSIDERAÇÕES FINAIS}

Muitos autores e obras têm avançado no sentido de delinear possibilidades educativas que possam concretizar na prática as intenções expressas nos conceitos de SAN e de PS. Contudo, avaliamos ser necessário, no atual contexto de exclusão social, dedicar mais estudos e reflexões críticas, na perspectiva de criar processos emancipatórios 
nas iniciativas educativas em saúde e SAN, o que deverá não só abrir novos horizontes para a ação do profissional de saúde e melhorar o estado de saúde das coletividades particularmente as populares -, mas também ressignificar efetivamente a saúde e sua aplicação na realidade social.

Cabe ponderar que cada processo educativo em saúde e SAN se dá em um território com particulares, em um contexto rico em vida, que é dinâmico, potente e cheio de complexidades. Assim, os profissionais não podem resolver tudo sozinhos, e a respostas aos problemas localmente identificados, no que tange à saúde, à alimentação e à nutrição, só poderão ser construídas a partir de um esforço e construção compartilhados entre os sujeitos de cada local, levando-se em consideração sua realidade, conhecendose as pessoas e dialogando com elas para encontrar saída para esses entraves. Esse é o caminho, em uma pedagogia construída de modo compartilhado com as pessoas.

A partir da experiência aqui estudada, avaliamos que é assim que se constrói um agir crítico em Saúde e em Nutrição na perspectiva da Educação Popular. Em nossa visão, a experiência do PINAB - objeto desta pesquisa - demonstra que, por meio da Educação Popular, podem-se delinear estratégias e caminhos participativos, críticos e amorosos de promoção da saúde e de fomento à SAN com os grupos sociais comunitários, o que oportunizou o desenvolvimento das atividades com parceria, proatividade e comprometimento. Processualmente, é tecida uma reorientação da nutrição e da saúde como prática social e profissional. E isso só ocorre porque a Educação Popular tem princípios, intencionalidades e abordagens capazes de trazer elementos para a superação da distância entre o debate crítico em torno da nutrição (principalmente no campo da SAN) e suas realizações no campo prático, particularmente as educacionais.

Mesmo com limites, a experiência do PINAB aponta provocações e caminhos suficientes para acreditarmos firmemente que a Educação Popular fundamenta uma teoria e uma prática de um agir crítico em PS e em SAN na Atenção Básica.

\section{REFERÊNCIAS}

1. Organização Mundial da Saúde (OMS). Carta de Ottawa. Ottawa: OMS; 1986.

2. Buss PM. Promoção da saúde e qualidade de vida. Ciênc. Saúde Coletiva. 2000; 5(1):163-77.

3. Buss PM, Pellegrini Filho A. A saúde e seus determinantes sociais. Physis. 2007; 17(1):77-93.

4. Pinheiro ARO. A alimentação saudável e a promoção da saúde no contexto da segurança alimentar e nutricional. Saúde em Debate. 2005; 29(70):125-39.

5. Ferreira VA, Mahalhães R. Nutrição e promoção da saúde: perspectivas atuais. Cad. Saúde Pública. 2007; 23(7):1674-81. 
6. Vasconcelos EM, Cruz PJSC, organizadores. Educação popular na formação universitária: reflexões com base em uma experiência. São Paulo: Hucitec; João Pessoa: UFPB; 2011.

7. Freire P, Nogueira A. Que fazer: teoria e prática em educação popular. 4a ed. Petrópolis: Vozes; 1993.

8. Gadamer H. Verdade e método. Petrópolis: Vozes; 1999.

9. Minayo MCS. O desafio do conhecimento: pesquisa qualitativa em saúde. 11a ed. São Paulo: Hucitec; 2008.

10. Camargo Junior KR, Bosi MLM. Metodologia qualitativa e pesquisa em saúde coletiva. Physis. 2011; 21(4):1187-90.

11. Sá-Silva JR, Almeida CD, Guindani JF. Pesquisa documental: pistas teóricas e metodológicas. RBHCS. 2009; 1(1):1-15.

12. Cruz PJSC, Vasconcelos ACCP, Araújo RS, organizadores. Pesquisa em extensão popular no Programa PINAB: produções acadêmicas em 2014. João Pessoa: Editora CCTA; 2016.

13. Cruz PJSC, et al. Educação popular e nutrição social: reflexões e vivências com base em uma experiência. João Pessoa: UFPB; 2014.

14. Holliday OJ. Para sistematizar experiências. Brasília: Ministério do Meio Ambiente; 2006.

15. Melo Neto JF. Dialética: uma visão marxista. In: Melo Neto JF, Cezarino H, Carneiro GM, organizadores. Dialética. 1a ed. João Pessoa: UFPB; 2002. p. 83-121.

16. Cruz PJSC. Agir crítico em nutrição: uma construção pela educação popular [tese]. João Pessoa (PB): Universidade Federal da Paraíba; 2015.

17. Carneiro DGB, et al. O agente comunitário de saúde e a promoção da segurança alimentar e nutricional na estratégia saúde da família: reflexões a partir de uma experiência educativa. Rev APS. 2010; 13(4):510-7.

18. Carneiro DGB, et al. Reconfigurando as ações do PINAB: novos caminhos, outros desafios. In: Cruz PJSC, et al. Educação popular e nutrição social: reflexões e vivências com base em uma experiência. João Pessoa: UFPB; 2014. p. 67-91.

Submissão: janeiro de 2019.

Aprovação: julho de 2020. 